\title{
Preparation and Property of Bio-Polyimide/Halloysite Nanocomposite Based on 2,5-Furandicarboxylic Acid
}

\author{
Yingxia Chen ${ }^{1}$, Shuya Fan ${ }^{1}$, Xibin $\mathrm{Yi}^{2}{ }^{2}$, Bing Li ${ }^{2}$, Shiwei Chen ${ }^{1,2}{ }^{*}$, Shuyu Liu ${ }^{1}$, Tao $\mathrm{Hu}^{1}$ and $\mathrm{Si}$ Chen ${ }^{1}$ \\ 1 Shandong Provincial Key Laboratory of Processing and Testing Technology of Glass and Functional Ceramics, \\ School of Material Science and Engineering, Qilu University of Technology (Shandong Academy of Sciences), \\ Jinan 250353, China; 13884894032@163.com (Y.C.); 15550913065@163.com (S.F.); shuyu031251@163.com (S.L.); \\ xixixiaohu1234@163.com (T.H.); chensi11233@163.com (S.C.) \\ 2 Shandong Key Laboratory for Special Silicon-containing Material, Advanced Materials Institute, \\ Qilu University of Technology (Shandong Academy of Sciences), Jinan 250014, China; yixb@sdas.org (X.Y.); \\ mindless000cn@163.com (B.L.) \\ * Correspondence: chenshiwei@qlu.edu.cn
}

Citation: Chen, Y.; Fan, S.; Yi, X.; Li, B.; Chen, S.; Liu, S.; Hu, T.; Chen, $\mathrm{S}$. Preparation and Property of Bio-Polyimide/Halloysite Nanocomposite Based on 2,5-Furandicarboxylic Acid. Polymers 2021, 13, 4057. https://doi.org/ $10.3390 /$ polym 13234057

Academic Editor: Amir Ameli

Received: 9 October 2021

Accepted: 17 November 2021

Published: 23 November 2021

Publisher's Note: MDPI stays neutral with regard to jurisdictional claims in published maps and institutional affiliations.

Copyright: () 2021 by the authors. Licensee MDPI, Basel, Switzerland. This article is an open access article distributed under the terms and conditions of the Creative Commons Attribution (CC BY) license (https:// creativecommons.org/licenses/by/ $4.0 /)$.

\begin{abstract}
Bio-based polyimide (PI)/halloysite nanotube (HNT) nanocomposites based on 2,5-furandicarboxylic acid were prepared by in situ polymerization. The pristine HNTs were modified by tetraethoxysilane (TEOS) and 4,4'-oxybisbenzenamine (ODA). The bio-based PI/HNT nanocomposite film exhibited lower moisture absorption than pure bio-based polyimide, showing that the water resistance of the bio-based polyimide film was improved. The thermal stability and glass transition temperature (Tg) of PI/HNTs nanocomposites were improved with the addition of modified HNTs. Both the tensile strength and Young's modulus of bio-based PI/HNTs nanocomposite films were enhanced. A $37.7 \%$ increase in tensile strength and a $75.1 \%$ increase in Young's modulus of bio-based PI/HNTs nanocomposite films, with $1 \mathrm{wt} \%$ of the modified HNTs, were achieved. The result confirmed that 2,5-furandicarboxylic acid could replace the oil-based material effectively, thus reducing pollution and protecting the environment. Finally, a preparation mechanism to prepare bio-based PI/HNTs nanocomposite is proposed.
\end{abstract}

Keywords: bio-based polyimide; halloysite nanotubes; thermal property; mechanical properties

\section{Introduction}

Polyimide (PI) is a particular kind of polymer, whose molecular chain contains an imide ring. The molecular chain of PI has many aromatic rings and heterocycles. PI shows excellent thermal stability, flame retardant, high insulation, a low dielectric constant, and high mechanical properties [1-6]. Notably, PI has the best thermal stability among the polymers and exhibits excellent comprehensive properties in each application field. Film was one of the earliest PI products. It is widely used in aerospace, microelectronics, atomic energy, electrical insulation, liquid crystal display, membrane separation technology, and other fields [7-11]. PI film is known as "gold film" and is the key to influencing the technical development of industries in many countries.

Recently, polyimide film has become more widely available in high-tech fields such as aeronautics and astronautics. These fields need high-temperature resistance of the polyimide film [12-14]. With the continuous development of modern industry and the expansion of applicable fields, it is urgent to prepare polyimide films with high-temperature resistance, strength, and modulus [15-17]. In order to improve the properties of polyimide films, much research on polyimide composite films has been conducted. The widely used solution was to add inorganic particles to polyimide films $[18,19]$. Fang prepared a novel PI composite film based on lithium bis(trifluoromethanesulfonyl)imide (LiTFSI). The PI/LiTFSI composite film, containing $15 \mathrm{wt} \%$ LiTFSI, displayed comprehensive property [20]. Zhao synthesized ultralong titanate nanotubes, which were used to prepare 
$\mathrm{PI} /$ titanate nanotube composite films. They found that PI/titanate nanotube composites exhibited improved electrical and mechanical properties compared to that of pure PI [21]. Shin prepared two series of transparent polyimide (PI) hybrid films with organically modified clay by solution intercalation polymerization and thermal imidization. They found that hybrids exhibited higher glass transition temperatures $(\mathrm{Tg})$ and mechanical properties, owing to the addition of the organically modified clay [22].

HNTs are naturally layered silicate nanotubes, which are abundantly available. The structure is similar to that of a carbon nanotube [23,24]. Carbon nanotubes are excellent additives in the composites; however, they are too expensive. In contrast, the price of HNTs is much cheaper than that of carbon nanotubes. Thus, HNTs are a good substitute for carbon nanotubes. The specific surface area of HNTs is $50 \mathrm{~m}^{2} / \mathrm{g}$, the pipe diameter is $8-17 \mathrm{~nm}$, and the pore volume is $0.2-0.4 \mathrm{~cm}^{3} / \mathrm{g}$. HNTs are novel 1D natural nanomaterials with a unique combination of natural availability, large aspect ratio, rich functionality, tubular nanostructure, high mechanical strength, and good biocompatibility. These characteristics generate exceptional mechanical, thermal, and biological properties for HNT-polymer nanocomposites at a low cost [25]. Therefore, HNTs could be used as good additives in high-performance polymer nanocomposites and multifunctional nanocomposites. In the last decade, HNTs have been widely used as an additive to modify polymers. HNTs can improve the mechanical properties, thermal stability, and flame retardancy of polymers [26-30]. Lisuzzo prepared Mater-Bi/halloysite nanocomposite materials that could be employed as a bioplastic alternative to petroleum-derived products [31]. They found that the HNTs could effectively enhance thermal and tensile performance. Huang prepared halloysite/agar-based nanocomposites and found that the tensile strength and elongation at break of nanocomposites increased remarkably with the increase in chitosan and/or halloysite content [32]. Yang prepared PEO/halloysite nanocomposites. Their result showed that the tensile strength of the nanocomposites was improved effectively compared to that of pure PEO [33]. In general, there are two crucial factors influencing the property of polymer/HNTs nanocomposites: a good dispersion of the HNTs in the polymer matrix and a desirable interfacial affinity between the HNTs and the polymer. Because of the hydrophilic surface and the negatively charged external surface, it remains difficult to achieve a good dispersion of HNTs in the polymer matrix $[24,25]$. Scientists grafted coupling agents on the surface of HNTs to enhance the dispersion of HNTs in the polymer matrix and interfacial interactions. In addition, Zhang used TEOS as a silica precursor and silane as a surface modifier to modify clay. They found that this silica shell on the surface of the clay had many silanol groups, which greatly promoted silylation of the clay [34].

Today, resource shortage and environmental pollution are becoming more and more serious [35-39]. Meanwhile, with increasing awareness of environmental protection, the industries that consume considerable non-renewable resources or seriously destroy the environment are facing severe challenges [40-42]. Research on renewable resources to replace non-renewable resources, such as coal, oil and natural gas, has become a major focal point. Nowadays, governments around the world are making efforts to study and use new energy. Bio-based material refers to products existing in the biological world. With global joint efforts, they have become a renewable resource with the highest global output [43-46]. Among them, 2,5-furandicarboxylic acid is the only biological monomer with a five-membered ring, which makes it the strongest and most structurally stable among the bio-based monomers [47-49]. Bio-based polymers based on 2,5-furandicarboxylic acid have attracted more and more attention from scientists.

Therefore, it is urgent to develop a bio-based polyimide composite film which can replace petroleum-based monomers, and which has excellent comprehensive properties.

Herein, we propose a new and effective approach to fabricate the bio-based PI/HNTs nanocomposite based on 2,5-furandicarboxylic acid via in situ polymerization. The study aims to prepare bio-based polyimide/halloysiste nanocomposite film for the first time. We expect to use the bio-based monomer to replace oil-based material, which could reduce 
environmental pollution. In addition, we want to improve the thermal stability and tensile property of bio-based polyimide film.

\section{Materials and Methods}

\subsection{Materials}

HNTs were supplied by SanXing High-New Material Company of Zaozhuang, China. 2,5-furandicarboxylic acid, 3,3,4,4-benzophenone tetracarboxylic dianhydride (BTDA) and ODA were supplied by Alfa Aesar, Shanghai, China. Dimethyl sulfoxide (DMSO), Et ${ }_{3} \mathrm{~N}$, TEOS, ethanol, trimethylamine $\left(\mathrm{Et}_{3} \mathrm{~N}\right)$, acetic anhydride, and $\mathrm{N}, \mathrm{N}$-dimethylacetamide (DMAc) were all reagent grades and provided by Beijing Chemical Reagents Company, Beijing, China. Deionized water was used in all experiments.

\subsection{Preparation of Modified HNTs}

Firstly, the dried HNTs (10.0 g) were dispersed in the mixtures of ethanol $(100.0 \mathrm{~mL})$ and ammonia $(18.4 \mathrm{~mL})$. The solution was kept stirring for $2 \mathrm{~h}$ at room temperature. Then the temperature was adjusted to $60{ }^{\circ} \mathrm{C}$ and TEOS $(2.0 \mathrm{~mL})$ was added with continuous stirring for $6 \mathrm{~h}$. Subsequently, the slurry was filtered, washed with ethanol several times, and dried at $110^{\circ} \mathrm{C}$ for $12 \mathrm{~h}$.

Secondly, the product above $(10.0 \mathrm{~g})$ was dispersed in the ethanol $(100.0 \mathrm{~mL})$ again and stirred for $2 \mathrm{~h}$. Meanwhile, ODA $(1.0 \mathrm{~g})$ was added into the slurry and was kept stirring for another $2 \mathrm{~h}$ at room temperature. Then the slurry was filtered, washed with ethanol several times, and dried at $110^{\circ} \mathrm{C}$ for $12 \mathrm{~h}$. The obtained power was the modified HNTs and was termed m-HNTs.

\subsection{Preparation of Bio-Based Diamine}

Firstly, 2,5-furandicarboxylic acid reacted with DMSO to prepare 2,5-furandicarbonyl dichloride according to the method reported by Ma et al. [50].

Secondly, DMAc $(30 \mathrm{~mL}), \mathrm{Et}_{3} \mathrm{~N}(24 \mathrm{mmol})$, and ODA $(24 \mathrm{mmol})$ was added in a three-necked flask and stirred for $15 \mathrm{~min}$ at room temperature. Under the condition of a $\mathrm{N}_{2}$ atmosphere, 2,5-furandicarbonyl dichloride $(20 \mathrm{mmol})$ in DMAc $(20 \mathrm{~mL})$ was added dropwise to this solution. After being stirred for another $24 \mathrm{~h}$, the mixture was poured into the water. Then, the precipitate occurred. Subsequently, the precipitate was filtrated, washed with water several times, and dried under a vacuum at $90{ }^{\circ} \mathrm{C}$. The product was named FDCA-OA and the product yield was $70 \%$.

\subsection{Preparation of Bio-Based PI/HNTs Nanocomposite}

m-HNTs $(0.05 \mathrm{~g})$ were dispersed in the DMAc $(10.0 \mathrm{~mL})$ and stirred for $2 \mathrm{~h}$. A $100 \mathrm{~mL}$ three-necked flask equipped with a nitrogen inlet tube and a mechanical stirrer was added with BTDA (1.90 g) and DMAc $(20.0 \mathrm{~mL})$. The solution was kept in $\mathrm{N}_{2}$ atmosphere for $1 \mathrm{~h}$. A homogeneous solution could be obtained when BTDA was completely dissolved. Bio-based diamine FDCA-OA was added into the flask and stirred for $3 \mathrm{~h}$. Subsequently, the mixtures of the m-HNTs and DMAc were put into the flask and stirred for $4 \mathrm{~h}$. Finally, a viscous and brown solution was obtained and subsequently used to prepare the films.

\subsection{Preparation of Bio-Based PI/HNTs Nanocomposites Films}

The solution above was sonicated for $30 \mathrm{~min}$ to remove gas bubbles. Then, the solution was poured into a clean glass plate and dried at $60^{\circ} \mathrm{C}$ for $12 \mathrm{~h}$ to evaporate the DMAc. Subsequently, the solution was step-cured (at each temperature of $100{ }^{\circ} \mathrm{C}, 200{ }^{\circ} \mathrm{C}, 250{ }^{\circ} \mathrm{C}$, and $300{ }^{\circ} \mathrm{C}$ for $1 \mathrm{~h}$ ). After curing, light yellowish films were obtained.

The films including $\mathrm{m}-\mathrm{HNTs} 1 \mathrm{wt} \%, 3 \mathrm{wt} \%$, and $5 \mathrm{wt} \%$ were denoted as PI-HNTs- $1 \%$, PI-HNTs-3\%, and PI-HNTs-5\%, respectively. To make the comparison, pure bio-based PI film was also prepared and named PI. The pristine HNTs were used to prepare the film, which was named PI-PHNTs-1\% when the content of the pristine HNTs was $1 \mathrm{wt} \%$. 


\subsection{Characterization}

The X-ray diffraction (XRD) spectra of all samples were obtained in a Siemens D-500 diffractometer with the angle $2 \theta$ from $10^{\circ}$ to $70^{\circ}$. The layer distance of HNTs could be obtained using the Bragg equation:

$$
d=\frac{n \lambda}{2 \sin \theta}
$$

where $n$ is an integer determined by the order given, $\lambda$ is the wavelength of the $\mathrm{CuK} \alpha$ radiation source, and $\theta$ is the angle. The microstructures of the samples were characterized in an FEI XL 30 scanning electron microscope (SEM) (Hillsboro, OR, USA) at $20 \mathrm{kV}$ acceleration voltage. Fourier-transform infrared (FTIR) spectra were obtained in a Spectrum 1000 Perkin-Elmer spectrometer (Waltham, MA, USA) in the spectral area of $400-4000 \mathrm{~cm}^{-1}$. Specimens were prepared by grinding the sample with potassium bromide $(\mathrm{KBr})$. Moisture absorption measurements of polyimide nanocomposite films (10 $\pm 2 \mathrm{um}$ ) were carried out in an environmental chamber at $30{ }^{\circ} \mathrm{C}$ for $72 \mathrm{~h}$ under $85 \%$ relative humidity. Specimens were cut into squares of $5 \times 5 \mathrm{~cm}^{2}$, annealed in an oven at $80^{\circ} \mathrm{C}$ for $24 \mathrm{~h}$, and cooled down to room temperature. The percentage of moisture absorption was calculated by the increase in weight divided by the original specimen weight. Thermogravimetric analysis (TGA) was carried out for the samples under nitrogen purge at a heating rate of $20^{\circ} \mathrm{C} / \mathrm{min}$ from $25^{\circ} \mathrm{C}$ to $800^{\circ} \mathrm{C}$ using a TG-DTA apparatus(STA449, Netzsch, Selb, Germany). Differential scanning calorimetry (DSC) was conducted by DSC SDT Q600 (TA, New Castle, DE, USA)with a heating rate of $10{ }^{\circ} \mathrm{C} / \mathrm{min}$ from $100{ }^{\circ} \mathrm{C}$ to $390{ }^{\circ} \mathrm{C}$ under $\mathrm{N}_{2}$ atmosphere to obtain the glass transition temperatures ( $\mathrm{Tg})$ of the samples. The measurement of the mechanical properties of films were tested by Instron testing machine Model 5567 according to ASTM D638. Average values of five specimens for each sample were reported.

\section{Results and Discussion}

\subsection{The Preparation Scheme of Bio-Based Polyimide/HNTs Films}

The scheme to prepare bio-based polyimide/HNTs nanocomposite is illustrated in Figure 1. Owing to the hydrolysis of TEOS, more $\mathrm{OH}$ groups covered the surface of the HNTs. These $\mathrm{OH}$ groups could have a chemical or physical interaction with the $\mathrm{NH}_{2}$ groups of the ODA. TEOS made the ODA modify the HNTs more efficiently. BTDA could have had a pre-polycondensation reaction with bio-based diamine to obtain linear polyamic acid. When the temperature went up to $150^{\circ} \mathrm{C}$, polyamic acid could have had a cross-linking reaction to obtain ring polyimide. Due to the polar groups, $\mathrm{m}$-HNTs could have had a chemical or physical interaction with the polyimide. Thus, the compatibility and interfacial interaction between $\mathrm{m}-\mathrm{HNTs}$ and polyimide matrix was improved, leading to strong structural stability and effective stress transfer. Finally, the improved tensile strength and Young's modulus of bio-based PI/HNTs nanocomposite film could be expected, compared to that of pure bio-based PI.

\subsection{Characterization of $m-H N T s$}

Halloysite is a hollow cylinder with a basal spacing $\left(\mathrm{d}_{001}\right)$ of $1 \mathrm{~nm}$. Halloysite has an internal surface composed of aluminol (Al-OH) groups and an external surface composed of siloxane ( $\mathrm{Si}-\mathrm{O}-\mathrm{Si})$ groups. A monolayer of water molecules is weakly held in the interlayer of halloysite. When the halloysite is dehydrated, the basal spacing of the interlayer can be reduced to $0.73 \mathrm{~nm}$ [51].

Figure 2 shows the XRD patterns of HNTs and m-HNTs. The typical diffraction peaks $\left(\mathrm{d}_{001}\right)$ at $2 \theta=12.1^{\circ}$ occurred in the spectrum of both HNTs and m-HNTs. According to the Bragg equation, the layer distance of two samples was $0.73 \mathrm{~nm}$. The typical diffraction peak on the spectrum was still at the same position, indicating that the TEOS and ODA did not insert into the interlayer space of HNTs. It is noted that the peak intensity (especially $2 \theta=12.1^{\circ}$ and $20.0^{\circ}$ ) of $\mathrm{m}$-HNTs decreased compared to HNTs. This could be attributed to the TEOS and ODA covered on the HNTs. The result showed that TEOS and ODA 
were grafted onto the surface of HNTs, which was in agreement with other reports [52]. The reason was that the strong hydrogen bond between the intersurface $\mathrm{Al}-\mathrm{OH}$ inside the interlayers could block other molecules from inserting into the layers. Finally, the modified agents were grafted onto the silanol groups on the surface or the edge of the HNTs.

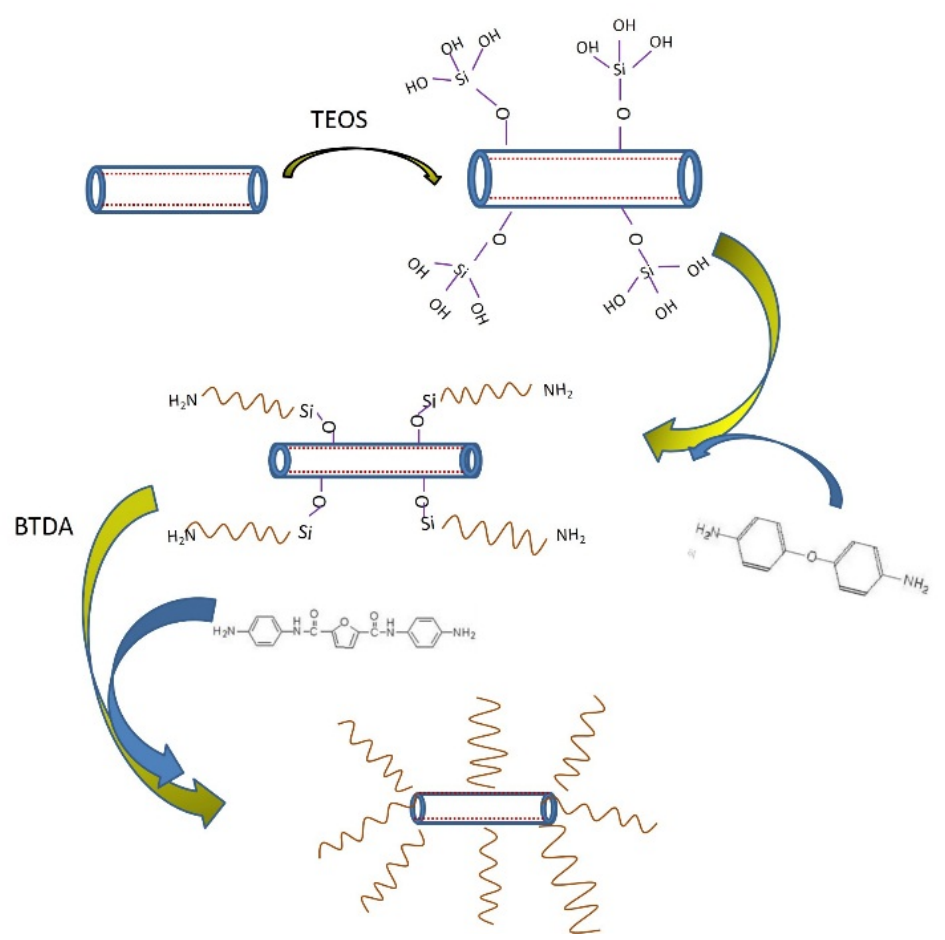

Figure 1. The preparation scheme to prepare bio-based polyimide/HNTs nanocomposite.

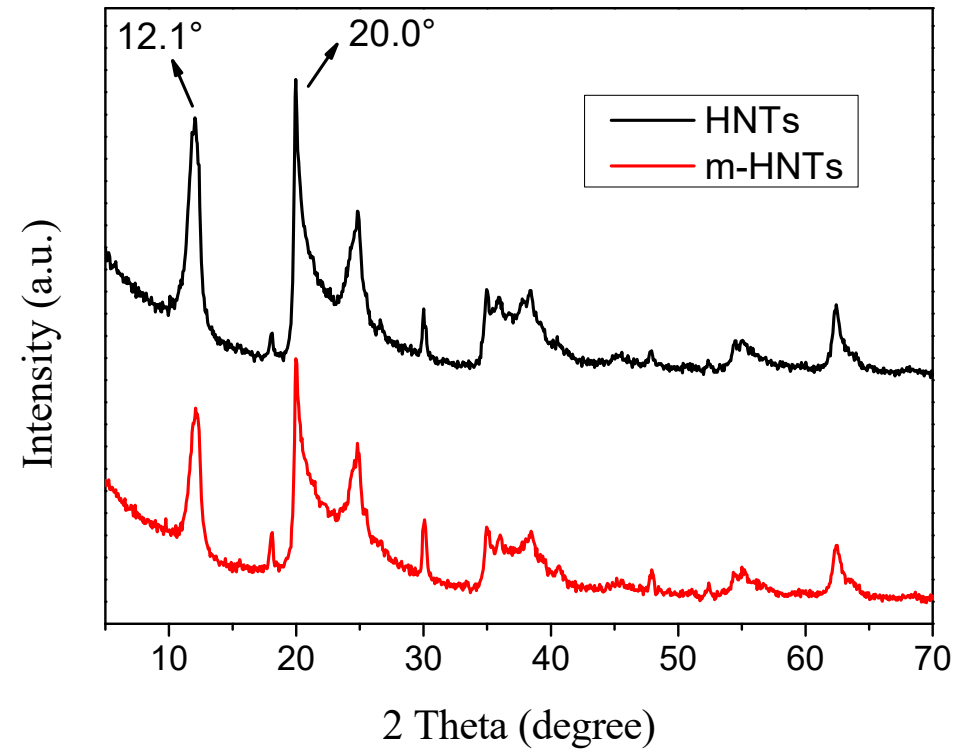

Figure 2. XRD patterns of HNTs and m-HNTs.

Figure 3 shows the FTIR spectra of HNTs and m-HNTs. According to Figure 3, the peak at $1103 \mathrm{~cm}^{-1}$ corresponded to a Si-O stretching band and the peak at $910 \mathrm{~cm}^{-1}$ was attributed to an $\mathrm{OH}$ vibration band. The peak at $536 \mathrm{~cm}^{-1}$ was ascribed to an Al-O-Si band [53]. It could be seen that the intensity of two peaks at $3400 \mathrm{~cm}^{-1}$ and $1650 \mathrm{~cm}^{-1}$ increased. The broad peak of water $\mathrm{OH}$ stretch, centered at $3400 \mathrm{~cm}^{-1}$, was further increased in the spectra of m-HNTs samples, which is attributed to the overlap with the 
$\mathrm{NH}_{2}$ stretching vibration signal around $3400 \mathrm{~cm}^{-1}$. Meanwhile, the peak at $1650 \mathrm{~cm}^{-1}$ was ascribed to the $\mathrm{OH}$ deformation of water. The peak intensity was also increased owing to a superposition with a $\mathrm{NH}_{2}$ deformation vibration signal around $1620 \mathrm{~cm}^{-1}$.

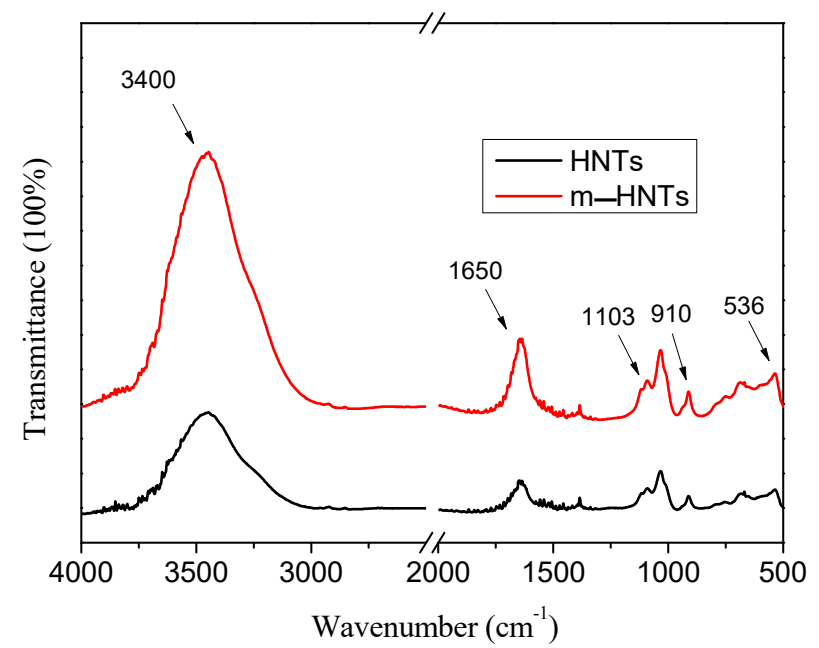

Figure 3. FTIR spectra of HNTs and m-HNTs.

Figure 4 shows the images of HNTs (a) and m-HNTs (b). It could be seen from (a) that the structure of the HNTs was tubular. The surface of the HNTs was smooth. According to (b), there are several obvious changes on the surfaces or the edges of m-HNTs compared to HNTs. The surface of m-HNTs became rough and some attachment was around the m-HNTs. The SEM images, accompanied with the FTIR and XRD results, confirmed that ODA molecules modified the HNTs.

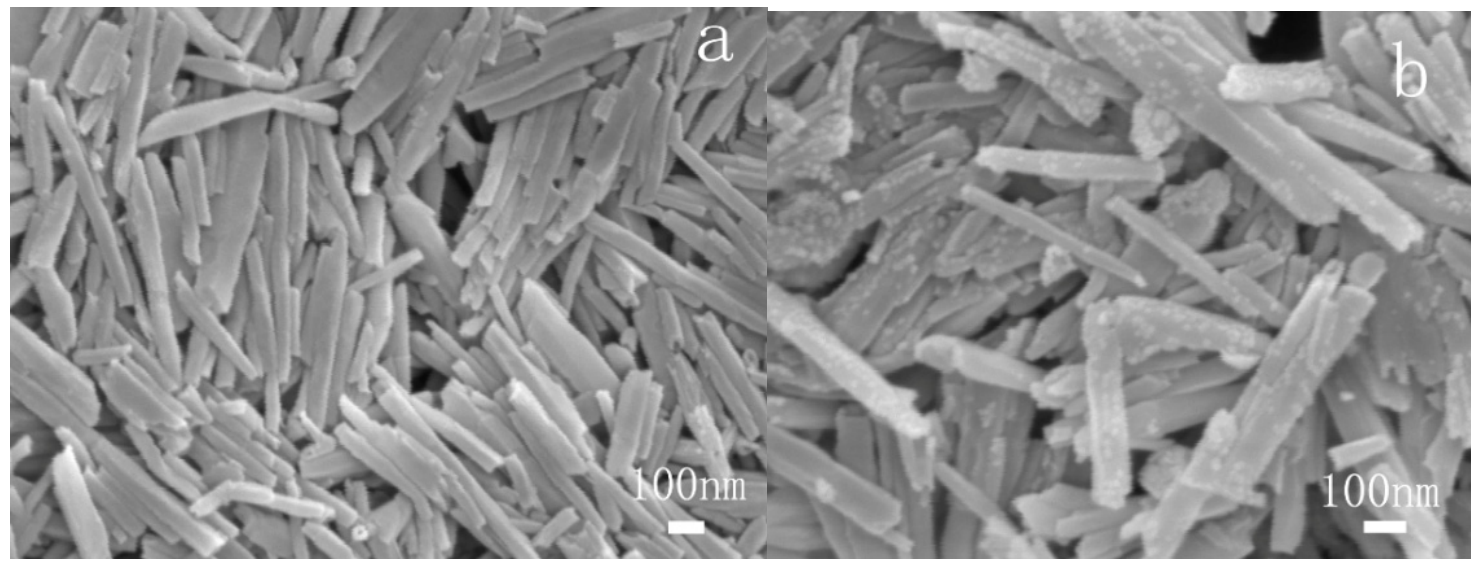

Figure 4. SEM images of HNTs (a) and m-HNTs (b).

\subsection{Characterization of PI-HNTs Film}

Figure 5 shows the SEM images of PI-HNTs-1\% (a), PI-PHNTs-1\% (b), PI-HNTs-3\% (c), and PI-HNTs-5\% (d). According to the figure, the surface of m-HNTs in the PI-HNTs- $1 \%$ was much more obscure and rougher than that of HNTs in the PI-PHNTs- $1 \%$. This is attributed to the polymer matrix covered on the surface. In addition, interfaces between PI and m-HNTs within PI-HNTs- $1 \%$ were obviously different from that between PI and HNTs within PI-PHNTs-1\%. The interface between PI and HNTs within PI-PHNTs-1\% was clear. The phenomenon displayed that m-HNTs had better compatibility with biobased polyimide film. This result confirmed that the modification of HNTs was beneficial for the compatibility between HNTs and bio-based polyimide. The reason was that the amino of the m-HNTs could be involved in the formation of a hydrogen bond and have a 
chemical reaction with bio-based polyimide film. According to Figure $5 \mathrm{c}$, PI-HNTs-3\%, and Figure 5d, PI-HNTs-5\%, more HNTs aggregated to big particles with the increase in HNTs.

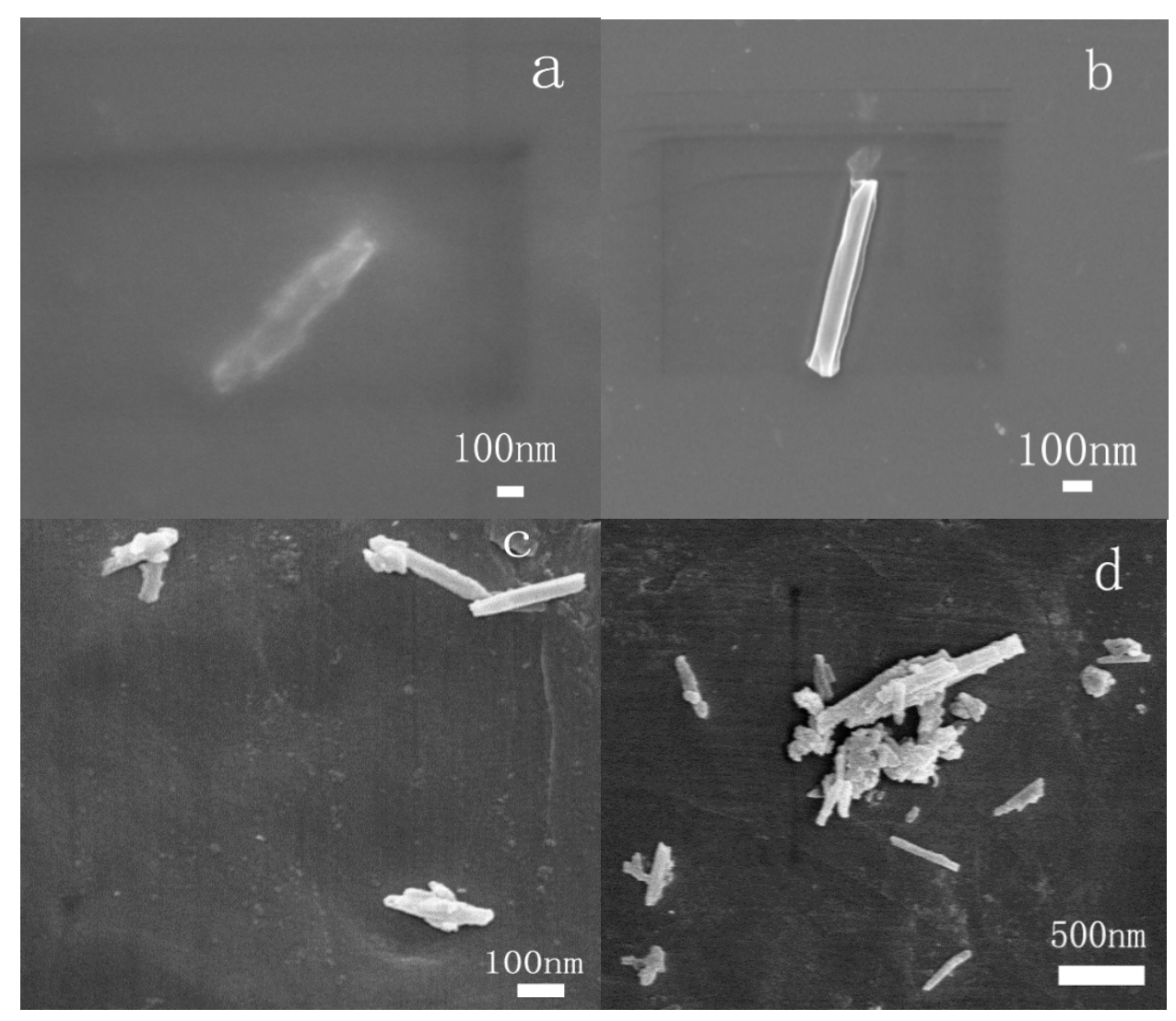

Figure 5. SEM of PI-HNTs-1\% (a), PI-PHNTs-1\% (b), PI-HNTs-3\% (c), and PI-HNTs-5\% (d).

Table 1 shows the molecular weights and molecular weight distribution of PI, PIPHNTs- $1 \%$, and PI-HNTs- $1 \%$. According to the table, the average molecular weight $(\mathrm{Mw})$ and the number average molecular weight (Mn) of PI-PHNTs- $1 \%$ and PI-HNTs- $1 \%$ were higher than that of PI. This is because the HNTs and m-HNTs could easily adsorb small monomer molecules and increase the local concentration of the monomer. The increased concentration benefited the polymerization and could enlarge the $\mathrm{Mw}$ and $\mathrm{Mn}$. It could also be found that the Mw and Mn of PI-HNTs- $1 \%$ were higher than those of PI-PHNTs- $1 \%$. The reason is as follows: firstly, the hydrogen bond between the amino groups of the m-HNTs and those of bio-based polyimide film could easily be formed, which could further increase the adsorption of small molecules; secondly, compared to HNTs, m-HNTs had better compatibility with bio-based polyimide film and there were fewer large aggregates, so the hindering effect on the molecular movement was weak. It is easier for a small monomer or a short polymer chain to move across each other and react, thus prolonging the polymer chain. In addition, Mw /Mn of PI-PHNTs- $1 \%$ and PI-HNTs- $1 \%$ were less than that of PI, showing that the HNTs and m-HNTs could influence the molecular weight distribution.

Table 1. The molecular weights and molecular weight distribution of PI, PI-PHNTs-1\%, and PI-HNTs-1\%.

\begin{tabular}{cccc}
\hline Samples & Mw & Mn & Mw/Mn \\
\hline PI & 113,106 & 79,614 & 1.42 \\
PI-PHNTs-1\% & 127,961 & 92,505 & 1.38 \\
PI-HNTs-1\% & 135,636 & 98,947 & 1.37 \\
\hline
\end{tabular}

Figure 6 displays XRD patterns of PI, PI-HNTs-1\%, PI-HNTs-3\%, and PI-HNTs-5\%. According to the figure, the typical diffraction peak at $2 \theta=12.1^{\circ}$ of HNTs was found in the 
curves of PI-HNTs-1\%, PI-HNTs-3\%, and PI-HNTs-5\%. The peak intensity increased with the increase in the halloysite. Two typically wide diffraction peaks at $2 \theta=17.8^{\circ}$ and $21.6^{\circ}$ of PI occurred on the curves of PI. At the addition of m-HNTs, the position of these two diffraction peaks changed. Meanwhile, these two wide diffraction peaks of PI gradually changed to a wide diffraction peak. The result showed that the m-HNTs could influence the crystal structure of the polyimide.

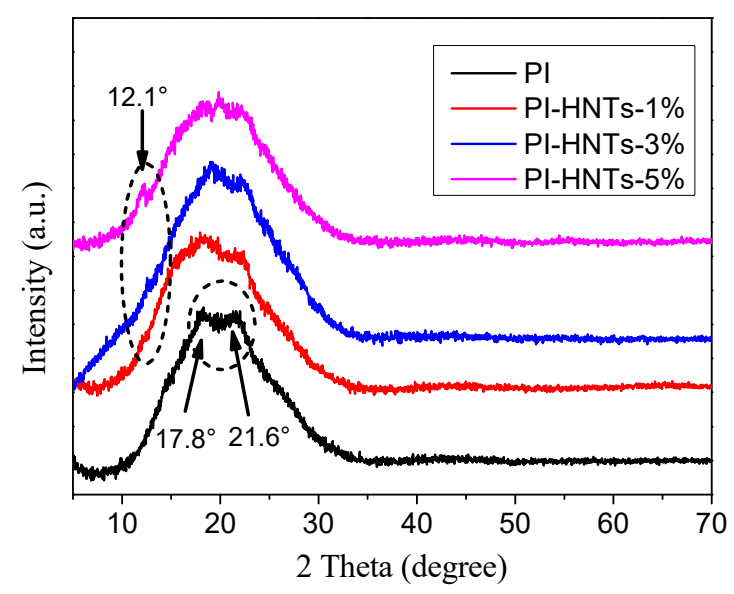

Figure 6. XRD patterns of PI, PI-HNTs-1\%, PI-HNTs-3\% and PI-HNTs-5\%.

Figure 7 shows DSC of PI, PI-HNTs-1\%, PI-HNTs-3\%, and PI-HNTs-5\%. As seen from the figure, Tg of PI-HNTs- $1 \%$, PI-HNTs-3\%, and PI-HNTs- $5 \%$ was $313.4{ }^{\circ} \mathrm{C}, 311.8{ }^{\circ} \mathrm{C}$ and $312.6^{\circ} \mathrm{C}$, which was larger than $309.8^{\circ} \mathrm{C}$ of PI. The result displayed that the $\mathrm{m}-\mathrm{HNTs}$ could influence the $\mathrm{Tg}$ of the bio-based polyimide film. This is because $\mathrm{m}-\mathrm{HNTs}$ could restrict the movement of the bio-based polyimide chain. It could be noted that PI-HNTs- $\%$ had the highest Tg. When the content of m-HNTs exceeded 1\%, Tg of PI-HNTs-3\% and PI-HNTs-5\% decreased. The reason was that more m-HNTs could gather to aggregates, which could not be dispersed well.

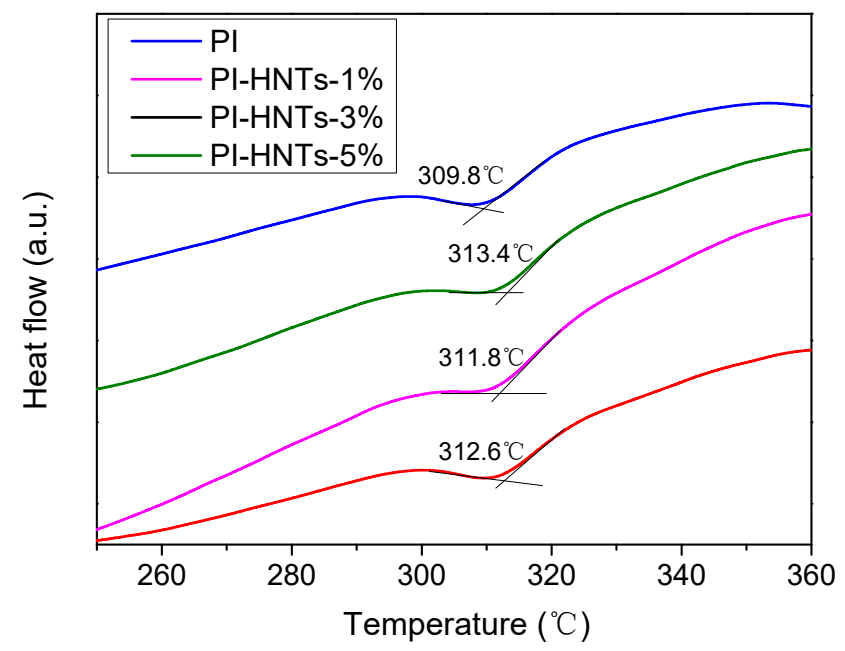

Figure 7. DSC of PI, PI-HNTs-1\%, PI-HNTs-3\%, and PI-HNTs-5\%.

Figure 8 shows the TGA (a) and DTG (b) curves of PI, PI-HNTs-1\%, PI-HNTs-3\%, and PI-HNTs-5\%. As shown in Figure $8 \mathrm{a}$ and Table 2, the temperatures of PI-HNTs-1\%, PI-HNTs-3\%, and PI-HNTs-5\% were $397.1{ }^{\circ} \mathrm{C}, 399.0^{\circ} \mathrm{C}$, and $403.3{ }^{\circ} \mathrm{C}$, which were higher than $390.1^{\circ} \mathrm{C}$ of PI. According to Table 3, the peak temperatures on the DTG curves of the samples were $601.3^{\circ} \mathrm{C}, 603.5^{\circ} \mathrm{C}$, and $608.6^{\circ} \mathrm{C}$, which were also larger than $596.9^{\circ} \mathrm{C}$ of PI. The peak temperature was ascribed to the largest decomposition rate of the polymer. 
Therefore, the result shows that the thermal stability of PI-HNTs increased compared to PI. The reason is as follows: Firstly, when the temperature was high enough, small and volatile molecules could be released from PI-HNTs films. m-HNTs could absorb these molecules and prevent their escape, thus inhibiting the degradation of the polymer; Secondly, mHNTs could absorb the heat and restrain the heat transfer; Thirdly, the good compatibility and physical or chemical interaction between $\mathrm{m}$-HNTs and the polyimide film could further prevent the heat transfer and the diffusion of volatile molecules. In addition, it can be seen that the pristine HNTs could also improve the thermal stability of PI. This is because: firstly, HNTs could slow down the escape of volatile products in the degradation process due to barrier; secondly, volatile products may be entrapped into the lumen of Hal, causing an effective delay of mass transport and, consequently, increased thermal stability entrapment effects. Meanwhile, the temperature $10 \mathrm{wt} \%$ loss of PI-PHNTs- $1 \%$ was lower than that of PI-HNTs- $1 \%$, showing that m-HNTs could improve the thermal stability of the PI more efficiently than pristine HNTs. The improved thermal stability is attributed to the barrier effect of the finely dispersed particles, which hindered the diffusion of small molecules generated during the thermal decomposition.
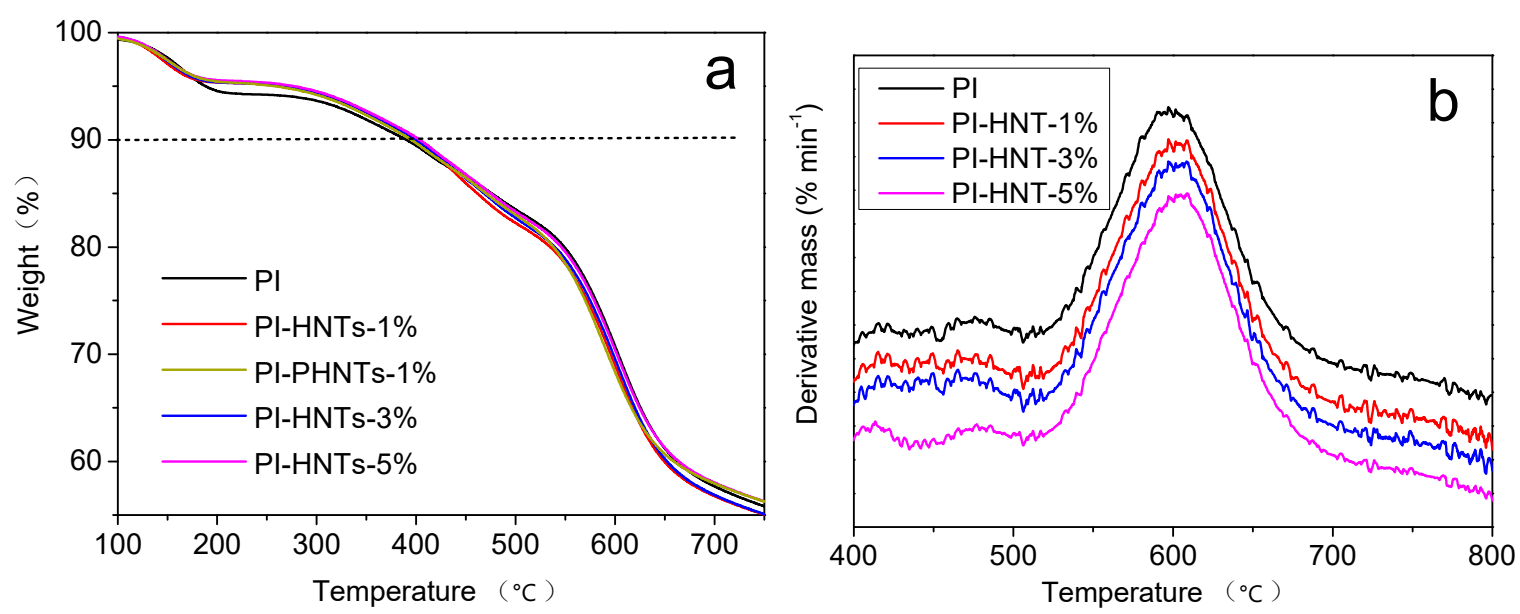

Figure 8. TGA (a) and DTG (b) curves of PI, PI-HNTs-1\%, PI-HNTs-3\%, and PI-HNTs-5\%.

Table 2. The decomposition temperatures of the samples at $10 \mathrm{wt} \%$ loss.

\begin{tabular}{cc}
\hline Samples & $\begin{array}{c}\text { Temperature }\left({ }^{\circ} \mathbf{C}\right) \\
\mathbf{1 0} \text { wt \% Loss }\end{array}$ \\
\hline PI & 390.1 \\
PI-HNTs-1\% & 397.1 \\
PI-PHNTs-1\% & 394.9 \\
PI-HNTs-3\% & 399.0 \\
PI-HNTs-5\% & 403.3 \\
\hline
\end{tabular}

Table 3. The peak temperatures of the samples of PI, PI-HNTs- $1 \%$, PI-HNTs-3\%, and PI-HNTs-5\%.

\begin{tabular}{cc}
\hline Samples & Peak Temperature $\left({ }^{\circ} \mathbf{C}\right)$ \\
\hline PI & 596.9 \\
PI-HNTs-1\% & 601.3 \\
PI-HNTs-3\% & 603.5 \\
PI-HNTs-5\% & 608.6 \\
\hline
\end{tabular}

Figure 9 shows the moisture absorption of PI, PI-HNTs-1\%, PI-PHNTs-1\%, PI-HNTs$3 \%$, and PI-HNTs- $5 \%$. The moisture of the bio-based polyamide film PI was $1.3 \%$. After the addition of m-HNTs, the moisture absorption of PI-HNTs- $1 \%$, PI-HNTs-3\%, and PIHNTs- $5 \%$ decreased. When the content of m-HNTs was $1 \%$, bio-based polyimide/HNTs 
film had the least moisture absorption, showing the PI-HNTs- $1 \%$ had the best water resistance. In order to compare the effort on the water resistance of bio-based polyimide film between pristine HNTs and modified HNTs, pristine HNTs were also added to the biobased polyimide film to obtain PI-PHNTs-1\%. Evidently, it could be seen that the moisture absorption of PI-PHNT-1\% was higher than that of PI. It is reported that $\mathrm{OH}$ groups on the halloysite were hydrophilic and the interface defect could easily occur between the polyimide film and halloysite, resulting in the water absorption of PI-PHNTs- $1 \%$ being higher than pure bio-based PI film. When the HNTs were modified, the introduction of ODA could improve the interface between the bio-based polyimide and HNTs. The interface defect could be reduced effectively. Therefore, the water resistance was improved. It is noted that water absorption of PI-HNTs- $3 \%$ and PI-HNTs- $5 \%$ increased compared to PI-HNTs- $1 \%$. This is because more aggregates occurred and made more defects.

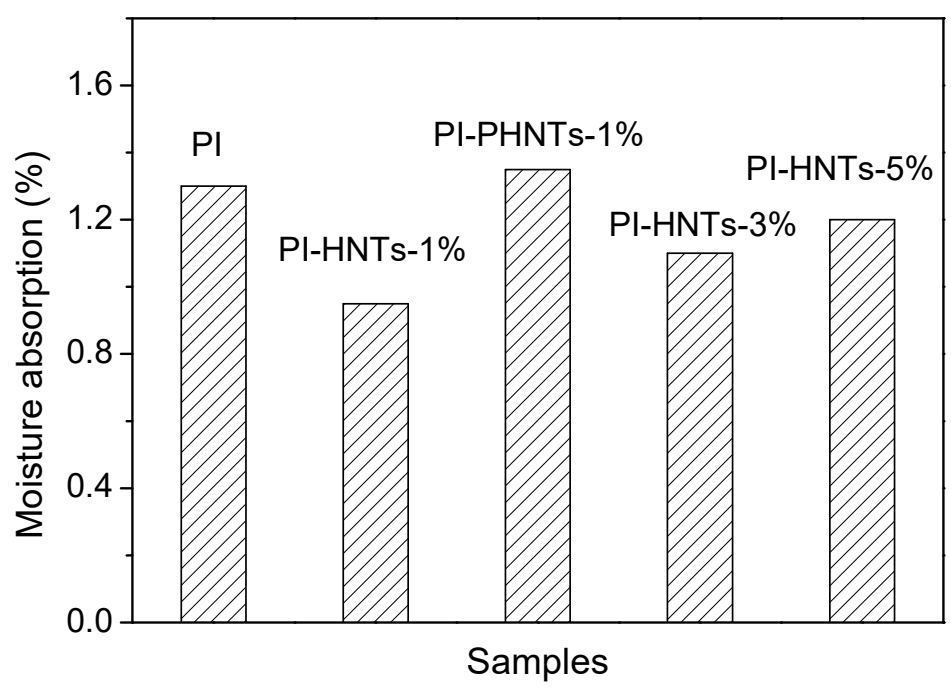

Figure 9. Moisture absorption of PI, PI-HNTs-1\%, PI-PHNTs-1\%, PI-HNTs-3\%, and PI-HNTs-5\%.

Table 4 displays the results of tensile strength, strain at break, and Young's modulus for the samples. It could be seen that the mechanical property of PI-HNTs-1\%, PI-HNTs-3\%, and PI-HNTs-5\% was improved compared to pure bio-based polyimide film. It confirmed that m-HNTs could effectively enhance the mechanical property of the bio-based polyimide. According to the table, the tensile strength of bio-based polyimide film PI was $79.02 \mathrm{MPa}$. After the addition of m-HNTs, the tensile strength of PI-HNTs-1\%, PI-HNTs-3\%, and PI-HNTs-5\% was increased to $108.85 \mathrm{MPa}, 97.71 \mathrm{MPa}$, and 91.30 MPa, respectively. The tensile strength of PI-HNTs- $1 \%$ was the highest, which increased by $37.7 \%$ compared to that of pure PI. This is attributed to good compatibility and interfacial interaction between m-HNTs and polymer matrix, which could reduce the stress concentration and thus afford much more stress distribution. Young's modulus of PI was $1308 \mathrm{MPa}$. In contrast, Young's modulus of PI-HNTs-1\%, PI-HNTs-3\%, and PI-HNTs-5\% was $2290 \mathrm{MPa}, 1380 \mathrm{MPa}$, and $1784 \mathrm{MPa}$, which increased by $75.1 \%, 5.5 \%$, and $36.4 \%$. This result showed that the PIHNTs had stronger stiffness and the ability to resist the deformation. The strain at break of PI-HNT-1\%, PI-HNTs-3\%, and PI-HNTs-5\% was $9.039 \%, 12.460 \%$, and $8.829 \%$, which increased by $22.0 \%, 68.2 \%$, and $19.1 \%$ compared to $7.410 \%$ of pure PI. It is reasonable that the interfacial surface between $\mathrm{m}$-HNTs and bio-based polyimide film was strong to improve the plasticity of the polyimide film. 
Table 4. Values of tensile strength, strain at break, and Young's modulus for all samples.

\begin{tabular}{cccc}
\hline Sample & $\begin{array}{c}\text { Tensile Strength } \\
\mathbf{( M P a )}\end{array}$ & $\begin{array}{c}\text { Strain at Break } \\
\mathbf{( \% )}\end{array}$ & $\begin{array}{c}\text { Young's Modulus } \\
\mathbf{( M P a )}\end{array}$ \\
\hline PI & 79.02 & 7.410 & 1308 \\
PI-HNTs-1\% & 108.85 & 9.039 & 2290 \\
PI-HNTs-3\% & 97.71 & 12.460 & 1380 \\
PI-HNTs-5\% & 91.30 & 8.829 & 1784 \\
\hline
\end{tabular}

\section{Conclusions}

The bio-based polyimide/HNTs nanocomposite based on 2,5-furandicarboxylic acid was successfully prepared. The HNTs were modified by TEOS and ODA. These two agents were grafted to the surface or the edge of the HNTs rather than intercalated into the interlayers. The surface of modified HNTs became rough compared to the pristine HNTs. The modified HNTs improved the water resistance and thermal stability of bio-based polyimide film. The tensile strength and Young's modulus of PI-HNTs-1\% were up to 108.85 $\mathrm{MPa}$ and $2290 \mathrm{MPa}$, increasing by $37.7 \%$ and $75.1 \%$ compared to those of pure PI. This work used the bio-based monomer to replace oil-based monomers successfully and supplied a method to prepare bio-polymer/HNTs nanocomposites.

Author Contributions: Conceptualization, Y.C. and S.C. (Shiwei Chen); methodology and investigation, Y.C.; software and validation, S.C. (Shiwei Chen) and X.Y.; formal analysis and data curation, Y.C., S.F. and S.C. (Shiwei Chen); writing-original draft preparation, Y.C.; writing-review and editing, S.C. (Shiwei Chen) and X.Y.; visualization, B.L. and S.L.; supervision, S.L. (Si Chen); project administration, T.H.; funding acquisition, S.C. (Shiwei Chen). All authors have read and agreed to the published version of the manuscript.

Funding: The authors are thankful for the support of the Natural Science Foundation of Shandong Province (Grant No. ZR2019BEM025); Young Doctor Cooperation Foundation of Qilu University of Technology (Shandong Academy of Sciences) (Grant No. 2019BSHZ0016); College Students Innovation and Entrepreneurship Training Program (Grant No. S201910431075; xj201810431071); and Science-Education-Industry Integration Innovation Pilot Project of Qilu University of Technology (Grant No. 2020KJC-GH13).

Institutional Review Board Statement: Not applicable.

Informed Consent Statement: Not applicable.

Data Availability Statement: We declare that the data supporting the findings of this study are available within the article.

Conflicts of Interest: The authors declare no conflict of interest. The founding sponsors had no role in the design of the study; in the collection, analyses, or interpretation of data; in the writing of the manuscript; and in the decision to publish the results.

\section{References}

1. Lee, Y.-J.; Huang, J.-M.; Kuo, S.-W.; Lu, J.-S.; Chang, F.-C. Polyimide and polyhedral oligomeric silsesquioxane nanocomposites for low-dielectric applications. Polymer 2005, 46, 173-181. [CrossRef]

2. Zhu, B.; Xie, S.; Xu, Z.; Xu, Y. Preparation and properties of the polyimide/multi-walled carbon nanotubes (MWNTs) nanocomposites. Compos. Sci. Technol. 2006, 66, 548-554. [CrossRef]

3. An, L.; Pan, Y.; Shen, X.; Lu, H.; Yang, Y. Rod-like attapulgite/polyimide nanocomposites with simultaneously improved strength, toughness, thermal stability and related mechanisms. J. Mater. Chem. 2008, 18, 4928-4941. [CrossRef]

4. Zhiping, S.; Hui, Z.; Yunhong, Z. Polyimides: Promising energy-storage materials. Angew. Chem. Int. Ed. 2010, $49,8444-8448$.

5. Cavallaro, G.; Lazzara, G.; Milioto, S. Dispersions of Nanoclays of Different Shapes into Aqueous and Solid Biopolymeric Matrices. Extended Physicochemical Study. Langmuir ACS J. Surf. Colloids 2010, 27, 1158-1167. [CrossRef]

6. Guo, H.; Meador, M.A.B.; McCorkle, L.; Quade, D.J.; Guo, J.; Hamilton, B.; Cakmak, M.; Sprowl, G. Polyimide Aerogels Cross-Linked through Amine Functionalized Polyoligomeric Silsesquioxane. ACS Appl. Mater. Interfaces 2011, 3, 546-552. [CrossRef] 
7. Luong, N.D.; Hippi, U.; Korhonen, J.; Soininen, A.J.; Ruokolainen, J.; Johansson, L.-S.; Nam, J.-D.; Sinh, L.H.; Seppälä, J. Enhanced mechanical and electrical properties of polyimide film by graphene sheets via in situ polymerization. Polymer 2011, 52, 5237-5242. [CrossRef]

8. Ha, H.W.; Choudhury, A.; Kamal, T.; Kim, D.-H.; Park, S.-Y. Effect of Chemical Modification of Graphene on Mechanical, Electrical, and Thermal Properties of Polyimide/Graphene Nanocomposites. ACS Appl. Mater. Interfaces 2012, 4, 4623-4630. [CrossRef] [PubMed]

9. $\quad$ Liaw, D.-J.; Wang, K.-L.; Huang, Y.-C.; Lee, K.-R.; Lai, J.-Y.; Ha, C.-S. Advanced polyimide materials: Syntheses, physical properties and applications. Prog. Polym. Sci. 2012, 37, 907-974. [CrossRef]

10. Meador, M.A.B.; Malow, E.J.; Silva, R.; Wright, S.; Quade, D.; Vivod, S.L.; Guo, H.; Guo, J.; Cakmak, M. Mechanically Strong, Flexible Polyimide Aerogels Cross-Linked with Aromatic Triamine. ACS Appl. Mater. Interfaces 2012, 4, 536-544. [CrossRef]

11. Wu, W.; Wang, K.; Zhan, M.-S. Preparation and Performance of Polyimide-Reinforced Clay Aerogel Composites. Ind. Eng. Chem. Res. 2012, 51, 12821-12826. [CrossRef]

12. Chen, S.; Slattum, P.; Wang, C.; Zang, L. Self-Assembly of Perylene Imide Molecules into 1D Nanostructures: Methods, Morphologies, and Applications. Chem. Rev. 2015, 115, 11967-11998. [CrossRef] [PubMed]

13. Mittal, G.; Dhand, V.; Rhee, K.Y.; Park, S.-J.; Lee, W.R. A review on carbon nanotubes and graphene as fillers in reinforced polymer nanocomposites. J. Ind. Eng. Chem. 2014, 21, 11-25. [CrossRef]

14. Yao, J.; Pantano, M.F.; Pugno, N.M.; Bastiaansen, C.W.; Peijs, T. High-performance electrospun co-polyimide nanofibers. Polymer 2015, 76, 105-112. [CrossRef]

15. Zhang, L.-B.; Wang, J.-Q.; Wang, H.-G.; Xu, Y.; Wang, Z.; Li, Z.; Mi, Y.-J.; Yang, S.-R. Preparation, mechanical and thermal properties of functionalized graphene/polyimide nanocomposites. Compos. Part A Appl. Sci. Manuf. 2012, 43, 1537-1545. [CrossRef]

16. Li, Y.; He, G.; Wang, S.; Yu, S.; Pan, F.; Wu, H.; Jiang, Z. Recent advances in the fabrication of advanced composite membranes. J. Mater. Chem. A 2013, 1, 10058-10077. [CrossRef]

17. Jiang, Y.; Li, X.; Yu, S.; Jia, L.; Zhao, X.; Wang, C. Reduced Graphene Oxide-Modified Carbon Nanotube/Polyimide Film Supported MoS2Nanoparticles for Electrocatalytic Hydrogen Evolution. Adv. Funct. Mater. 2015, 25, 2693-2700. [CrossRef]

18. Qiu, X.; Wang, H.; Zhou, C.; Li, D.; Liu, Y.; Yan, C. Polyimide/kaolinite composite films: Synthesis and characterization of mechanical, thermal and waterproof properties. J. Taiwan Inst. Chem. Eng. 2014, 45, 2021-2028. [CrossRef]

19. Takassi, M.A.; Zadehnazari, A.; Farhadi, A.; Mallakpour, S. Highly stable polyimide composite films based on 1,2,4-triazole ring reinforced with multi-walled carbon nanotubes: Study on thermal, mechanical, and morphological properties. Prog. Org. Coat. 2015, 80, 142-149. [CrossRef]

20. Fang, D.; Yao, K.; Ding, Y.; Li, P.; Hou, H. High dielectric polyimide composite film filled with a heat-resistant organic salt. Compos. Commun. 2019, 14, 29-33. [CrossRef]

21. Zhao, H.; Yang, C.; Li, N.; Yin, J.; Feng, Y.; Liu, Y.; Li, J.; Li, Y.; Yue, D.; Zhu, C.; et al. Electrical and mechanical properties of polyimide composite films reinforced by ultralong titanate nanotubes. Surf. Coat. Technol. 2019, 360, 13-19. [CrossRef]

22. Shin, H.I.; Chang, J.-H. Transparent Polyimide/Organoclay Nanocomposite Films Containing Different Diamine Monomers. Polymers 2020, 12, 135. [CrossRef] [PubMed]

23. Danyliuk, N.; Tomaszewska, J.; Tatarchuk, T. Halloysite nanotubes and halloysite-based composites for environmental and biomedical applications. J. Mol. Liq. 2020, 309, 113077. [CrossRef]

24. Cheng, C.; Song, W.; Zhao, Q.; Zhang, H. Halloysite nanotubes in polymer science: Purification, characterization, modification and applications. Nanotechnol. Rev. 2020, 9, 323-344. [CrossRef]

25. Yuan, P.; Tan, D.; Annabi-Bergaya, F. Properties and applications of halloysite nanotubes: Recent research advances and future prospects. Appl. Clay Sci. 2015, 112-113, 75-93. [CrossRef]

26. Bertolino, V.; Cavallaro, G.; Milioto, S.; Lazzara, G. Polysaccharides/Halloysite nanotubes for smart bionanocomposite materials. Carbohydr. Polym. 2020, 245, 116502. [CrossRef]

27. Albdiry, M.; Yousif, B. Toughening of brittle polyester with functionalized halloysite nanocomposites. Compos. Part B Eng. 2018, 160, 94-109. [CrossRef]

28. Hong, M.C.; Ahn, H.; Choi, M.C.; Lee, Y.; Kim, J.; Rhee, H. Pd nanoparticles immobilized on PNIPAM-halloysite: Highly active and reusable catalyst for Suzuki-Miyaura coupling reactions in water. Appl. Organomet. Chem. 2014, 28, 156-161. [CrossRef]

29. Liu, M.; Zhang, Y.; Zhou, C. Nanocomposites of halloysite and polylactide. Appl. Clay Sci. 2013, 75-76, 52-59. [CrossRef]

30. Dong, Y.; Marshall, J.; Haroosh, H.J.; Mohammadzadehmoghadam, S.; Liu, D.; Qi, X.; Lau, K.-T. Polylactic acid (pla)/halloysite nanotube (hnt) composite mats: Influence of hnt content and modification. Compos. Part A Appl. Sci. Manuf. 2015, 76, 28-36. [CrossRef]

31. Lisuzzo, L.; Cavallaro, G.; Milioto, S.; Lazzara, G. Effects of halloysite content on the thermo-mechanical performances of composite bioplastics. Appl. Clay Sci. 2019, 185, 105416. [CrossRef]

32. Huang, D.; Zhang, Z.; Zheng, Y.; Quan, Q.; Wang, W.; Wang, A. Synergistic effect of chitosan and halloysite nanotubes on improving agar film properties. Food Hydrocoll. 2019, 101, 105471. [CrossRef]

33. Yang, K.; Chi, Q.W.; Wang, X.Y.; Jiang, Y.S.; Li, F.F.; Xue, B. The role of halloy site on crystallinity, ion conductivity, thermal and mechanical properties of poly(ethylene-oxide)/halloysite nanocomposites. J. Polym. Res. 2019, 26, 138. [CrossRef] 
34. Zhang, Q.; Liu, Q.; Mark, J.E.; Noda, I. A novel biodegradable nanocomposite based on poly (3-hydroxybutyrate-co-3hydroxyhexanoate) and silylated kaolinite/silica core-shell nanoparticles. Appl. Clay Sci. 2009, 46, 51-56. [CrossRef]

35. Zhao, X.; Zhang, J.; Wang, X.; Liu, B.; Yi, X. Polyimide aerogels crosslinked with MWCNT for enhanced visible-light photocatalytic activity. Appl. Surf. Sci. 2019, 478, 266-274. [CrossRef]

36. Zhao, X.; Yi, X.; Wang, X.; Chu, W.; Guo, S.; Zhang, J.; Liu, B.; Liu, X. Constructing efficient polyimide(pi)/ag aerogel photocatalyst by ethanol supercritical drying technique for hydrogen evolution. Appl. Surf. Sci. 2020, 502, 144187. [CrossRef]

37. Jiang, W.; Zong, X.; An, L.; Hua, S.; Miao, X.; Luan, S.; Wen, Y.; Tao, F.F.; Sun, Z. Consciously Constructing Heterojunction or Direct Z-Scheme Photocatalysts by Regulating Electron Flow Direction. ACS Catal. 2018, 8, 2209-2217. [CrossRef]

38. Meng, P.; Heng, H.; Sun, Y.; Liu, X. In situ polymerization synthesis of Z-scheme tungsten trioxide/polyimide photocatalyst with enhanced visible-light photocatalytic activity. Appl. Surf. Sci. 2018, 428, 1130-1140. [CrossRef]

39. Cuicui, W.; Yong, G.; Yu, Y.; Sheng, C.; Chenkun, Z.; Ying, W.; Zhigang, Z. Sulfur-doped polyimide photocatalyst with enhanced photocatalytic activity under visible light irradiation. ACS Appl. Mat. Inter. 2014, 6, 4321.

40. Xiaodong, J.; Zikun, W.; Zhen, W.; Jingling, Y. Bio-based poly(ether imide)s from isohexide-derived isomeric dianhydrides. Polymers 2017, 9, 569 .

41. Gaili, Y.; Rui, Z.; Huahua, H.; Lixin, L.; Lei, W.; Chen, Y. Synthesis of novel biobased polyimides derived from isomannide with good optical transparency, solubility and thermal stability. RSC Adv. 2015, 5, 67574-67582.

42. Hu, J.; Wang, Z.; Zheng, L.; Chang, C.; Gang, Y. Bio-based adenine-containing high performance polyimide. Polymer 2017, 119, 59-65. [CrossRef]

43. Kuhire, S.S.; Sharma, P.; Chakrabarty, S.; Wadgaonkar, P.P. Partially bio-based poly(amide imide)s by polycondensation of aromatic diacylhydrazides based on lignin-derived phenolic acids and aromatic dianhydrides: Synthesis, characterization, and computational studies. J. Polym. Sci. Part A Polym. Chem. 2017, 55, 3636-3645. [CrossRef]

44. Ji, X.; Wang, Z.; Yan, J.; Wang, Z. Partially bio-based polyimides from isohexide-derived diamines. Polymer 2015, 74, 38-45. [CrossRef]

45. Shin, H.; Wang, S.; Tateyama, S.; Kaneko, D.; Kaneko, T. Preparation of a Ductile Biopolyimide Film by Copolymerization. Ind. Eng. Chem. Res. 2016, 55, 8761-8766. [CrossRef]

46. Suvannasara, P.; Tateyama, S.; Miyasato, A.; Matsumura, K.; Shimoda, T.; Ito, T.; Yamagata, Y.; Fujita, T.; Takaya, N.; Kaneko, T. Biobased Polyimides from 4-Aminocinnamic Acid Photodimer. Macromolecules 2014, 47, 1586-1593. [CrossRef]

47. Luo, K.; Wang, Y.; Yu, J.; Zhu, J.; Hu, Z. Semi-bio-based aromatic polyamides from 2,5-furandicarboxylic acid: Toward highperformance polymers from renewable resources. RSC Adv. 2016, 6, 87013-87020. [CrossRef]

48. Gomes, M.; Gandini, A.; Silvestre, A.J.D.; Reis, B. Synthesis and characterization of poly(2,5-furan dicarboxylate)s based on a variety of diols. J. Polym. Sci. Part A Polym. Chem. 2011, 49, 3759-3768. [CrossRef]

49. Knoop, R.; Vogelzang, W.; Haveren, J.V.; Es, D. High molecular weight poly(ethylene-2,5-furanoate); critical aspects in synthesis and mechanical property determination. J. Polym. Sci. Part A Polym. Chem. 2013, 51, 4191-4199. [CrossRef]

50. Ma, K.; Chen, G.; Wang, W.; Zhang, A.; Zhong, Y.; Zhang, Y.; Fang, X. Partially bio-based aromatic polyimides derived from 2,5-furandicarboxylic acid with high thermal and mechanical properties. J. Polym. Sci. Part A Polym. Chem. 2018, 56, 1058-1066. [CrossRef]

51. Barrientos-Ramírez, S.; de Oca-Ramírez, G.M.; Ramos-Fernandez, E.V.; Sepúlveda-Escribano, A.; Pastor-Blas, M.M.; GonzálezMontiel, A. Surface modification of natural halloysite clay nanotubes with aminosilanes. Application as catalyst supports in the atom transfer radical polymerization of methyl methacrylate. Appl. Catal. A Gen. 2011, 406, 22-33. [CrossRef]

52. Yuan, P.; Southon, P.D.; Liu, Z.W.; Green, M.E.R.; Hook, J.M.; Antill, S.J.; Kepert, C.J. Functionalization of halloysite clay nanotubes by grafting with gamma-aminopropyltriethoxysilane. J. Phys. Chem. C 2008, 112, 15742-15751. [CrossRef]

53. Tierrablanca, E.; Romero-García, J.; Roman, P.; Cruz-Silva, R. Biomimetic polymerization of aniline using hematin supported on halloysite nanotubes. Appl. Catal. A Gen. 2010, 381, 267-273. [CrossRef] 